\title{
Weihgted Cesaro Sequence Space and Related Matrix Transformation
}

\author{
Md. Fazlur Rahman, A. B. M. Rezaul Karim* \\ Department of Mathematics, Eden University College, Dhaka, Bangladesh \\ Email address: \\ dr_mf_rahman@yahoo.com (Md. F. Rahman),abmreza27@gmail.com (A. B. M. R. Karim)
}

\section{To cite this article:}

Md. Fazlur Rahman, A. B. M. Rezaul Karim. Weihgted Cesaro Sequence Space and Related Matrix Transformation. Pure and Applied Mathematics Journal. Vol. 4, No. 6, 2015, pp. 237-241. doi: 10.11648/j.pamj.20150406.12

\begin{abstract}
In this paper we define the weighted Cesaro sequence spaces ces $(p, q)$. We prove the space $\operatorname{ces}(p, q)$ is a complete paranorm space. In section-2 we determine its Kothe-Toeplitz dual and continuous dual. In section-3 we establish necessary and sufficient condition for a matrix A to map ces $(p, q)$ to $l_{\infty}$ and $\operatorname{ces}(p, q)$ to $c$, where $l_{\infty}$ is the space of all bounded sequences and $c$ is the space of all convergent sequences. We also get some known and unknown interesting results as corollaries.
\end{abstract}

Keywords: Sequence Space, Kothe-Toeplitz Dual, Matrix Transformation

\section{Introduction}

Let $\omega$ be the space of all (real or complex) sequences and let $l_{\infty}$ and $c$ respectively the Banach spaces of bounded and convergent sequence $x=\left(x_{n}\right)$ endowed with the norm

$$
|| x||=\sup _{k \geq 1}\left|x_{k}\right|
$$

In [8] Shiue introduce the Cesaro sequence space $c e s_{p}$ as

$$
\operatorname{ces}_{p}=\left\{x=\left(x_{k}\right) \in \omega: \sum_{n=1}^{\infty}\left(\frac{1}{n} \sum_{k=1}^{n}\left|x_{k}\right|\right)^{p}<\infty\right\} \text { for } 1<p
$$

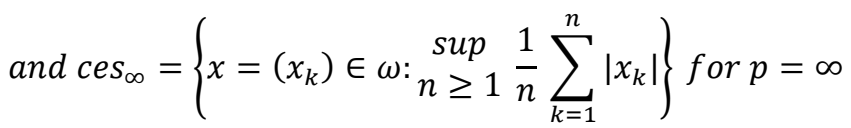

In [4] Leibowitz studied some properties of this space and showed that it is a Banach space. Lim [9] defined this space in a different norm as

$$
\operatorname{ces}_{p}=\left\{x=\left(x_{k}\right) \in \omega: \sum_{r=0}^{\infty}\left(\frac{1}{2^{r}} \sum_{r}\left|x_{k}\right|\right)^{p}<\infty\right\} \text { for } 1<p
$$

and

$$
\operatorname{ces}_{\infty}=\left\{x=\left(x_{k}\right) \in \omega: \sup _{r \geq 0} \frac{1}{2^{r}}\left|x_{k}\right|<\infty\right\} \text { for } p=\infty
$$

where $\sum_{r}$ denotes a sum over the ranges $\left[2^{r}, 2^{r+1}\right)$, determined its dual spaces and characterize some matrix classes. Later in [10] Lim extended this space $\operatorname{ces}_{p}$ to $\operatorname{ces}(p)$ for the sequence $p=\left(p_{r}\right)$ with inf $p_{r}>0$ and defined as

$$
\operatorname{ces}(p)=\left\{x=\left(x_{k}\right) \in \omega: \sum_{r=0}^{\infty}\left(\frac{1}{2^{r}} \sum_{r}\left|x_{k}\right|\right)^{p_{r}}<\infty\right\} \text {. }
$$

For positive sequence of real numbers $\left(p_{n}\right),\left(q_{n}\right)$ and $Q_{n}=q_{1}+q_{2}+\cdots+q_{n}$

Johnson and Mohapatra [11] defined the Cesaro sequence space $\operatorname{ces}(p, q)$ as

$$
\operatorname{ces}(p, q)=\left\{x=\left(x_{k}\right) \in \omega: \sum_{n=1}^{\infty}\left(\frac{1}{Q_{n}} \sum_{k=1}^{n} q_{k}\left|x_{k}\right|\right)^{p_{r}}<\infty\right\}
$$

and studied some inclusion relations.

What amounts to the same thing defined by Khan and Rahman [3] as

$$
\operatorname{ces}(p, q)=\left\{x=\left(x_{k}\right) \in \omega: \sum_{r=0}^{\infty}\left(\frac{1}{Q_{2} r} \sum_{r} q_{k}\left|x_{k}\right|\right)^{p_{r}}<\infty\right\}
$$

For $p=\left(p_{r}\right)$ with inf $p_{r}>0, Q_{2^{r}}=q_{2^{r}+} q_{2^{r}+1}+\cdots+$ $q_{2^{r+1}-1}$ and $\sum_{r}$ denotes a sum over the ranges $\left[2^{r}, 2^{r+1}\right.$ ). 
They determined it's Kothe -Toeplitz dual and characterized some matrix classes.

In this paper we define the Cesaro weighted sequence space $\operatorname{ces}(p, q)$ in the following way.

Definition. If $\left(q_{n}\right)$ is a bounded sequence of positive real numbers, then for $p=\left(p_{r}\right)$ with inf $p_{r}>0$, the Cesaro weighted sequence space $\operatorname{ces}(p, q)$ is defined by

$$
\operatorname{ces}(p, q)=\left\{x=\left(x_{k}\right) \in \omega: \sum_{r=0}^{\infty}\left(\frac{1}{Q_{2^{r}}} \sum_{r}\left|q_{k} x_{k}\right|\right)^{p_{r}}<\infty\right\}
$$

where $Q_{2} r=q_{2^{r}+} q_{2^{r+1}}+\cdots+q_{2^{r+1}-1}$ and $\sum_{r}$ denotes a sum over the range $2^{r} \leq k<2^{r+1}$.

If $q_{n}=1$ for all $n$, then $\operatorname{ces}(p, q)$ reduces to $\operatorname{ces}(p)$ studied by $\operatorname{Lim}[10]$. Also, if $p_{n}=p$ for all $\mathrm{n}$ and $q_{n}=1$ for all $\mathrm{n}$, then $\operatorname{ces}(p, q)$ reduces to $\operatorname{ces}_{p}$ studied also $\operatorname{Lim}[9]$. Obviously, $l(p) \subset \operatorname{ces}(p) \subset \operatorname{ces}(p, q)$ for $p_{r} \geq 1$.

In their paper [1] Maji and Srivastava defined the weighted Cesaro sequence space $\operatorname{ces}(p, q)$ with a different norms and studied on some operators and inclusion results.

The main purpose of this note is to define and investigate the weighted Cesaro sequence space $\operatorname{ces}(p, q)$, determine its Kothe-Toeplitz dual and characterize the class of matrices $\left(\operatorname{ces}(p, q), l_{\infty}\right)$ and $(\operatorname{ces}(p, q), c)$, where $l_{\infty}$ and $c$ are respectively the spaces of bounded and convergent complex sequences. By specializing sequences $\left(p_{n}\right)$ and $\left(q_{n}\right)$, we get the results of $\operatorname{Lim}([9],[10])$ as corollaries. Meanwhile, we also determine all continuous linear functional on $\operatorname{ces}(p, q)$ for all $1<p_{r}<\infty$.

With regard to notation, the dual space of $\operatorname{ces}(p, q)$, i.e, the space of all continuous linear functionals on $\operatorname{ces}(p, q)$, will be denoted by $\operatorname{ces}^{*}(p, q)$. We write

$$
A_{r}(n)=\max _{r}\left|\frac{a_{n, k}}{q_{k}}\right|
$$

where for each $n$ the maximum with respect to $\mathrm{k}$ in $\left[2^{r}, 2^{r+1}\right)$.

Throughout the paper the following well-known inequality (see [6] or [7]) will be frequently used. For any $E>0$ and any two complex numbers $a$ and $b$ we have

$$
\begin{gathered}
\quad|a b| \leq E\left(|a|^{t} E^{-t}+|b|^{t}\right) \\
\text { Where } p>1 \text { and } \frac{1}{p}+\frac{1}{q}=1
\end{gathered}
$$

To begin with, we show that the space $\operatorname{ces}(p, q)$ is paranormed by

$$
\begin{gathered}
g(x)=\left(\sum_{r=0}^{\infty}\left(\frac{1}{Q_{2} r} \sum_{r}\left|q_{k} x_{k}\right|\right)^{p_{r}}\right)^{1 / M} \\
\text { Provided } H=\sup _{r} p_{r}<\infty \text { and } M=\max \{1, H\}
\end{gathered}
$$

Clearly

$$
\begin{gathered}
g(\theta)=0 \\
g(-x)=g(x),
\end{gathered}
$$

where $\theta=(0,0,0, \ldots)$

Since $\quad p_{r} \leq M, M \geq 1$ so for any $x, y \in \operatorname{ces}(p, q)$ we have by Minkowski's inequality

$$
\begin{gathered}
\left(\sum_{r=0}^{\infty}\left(\frac{1}{Q_{2} r} \sum_{r}\left|q_{k}\left(x_{k}+y_{k}\right)\right|\right)^{p_{r}}\right)^{1 / M} \\
\leq\left(\sum_{r=0}^{\infty}\left(\frac{1}{Q_{2} r} \sum_{r}\left(\left|q_{k} x_{k}\right|+\left|q_{k} y_{k}\right|\right)\right)^{p_{r}}\right)^{1 / M}
\end{gathered}
$$

$\leq\left(\sum_{r=0}^{\infty}\left(\frac{1}{Q_{2^{r}}} \sum_{r}\left|q_{k} x_{k}\right|\right)^{p_{r}}\right)^{1 / M}+\left(\sum_{r=0}^{\infty}\left(\frac{1}{Q_{2^{r}}} \sum_{r}\left|q_{k} y_{k}\right|\right)^{p_{r}}\right)^{1 / M}$

which shows that $g$ is subadditive.

Finally we have to check the continuity of scalar multiplication. From the definition of $\operatorname{ces}(p, q)$, we have inf $\mathrm{p}_{\mathrm{r}}>0$. So, we may assume that inf $p_{r} \equiv \rho>0$. Now for any complex $\lambda$ with $\|\lambda\|<1$, we have

$$
\begin{gathered}
g(\lambda x)=\left(\sum_{r=0}^{\infty}\left(\frac{1}{Q_{2^{r}}} \sum_{r}\left|\lambda q_{k} x_{k}\right|\right)^{p_{r}}\right)^{1 / M} \\
=|\lambda|^{p_{r} / M}\left(\sum_{r=0}^{\infty}\left(\frac{1}{Q_{2^{r}}} \sum_{r}\left|q_{k} x_{k}\right|\right)^{p_{r}}\right)^{1 / M} \\
\leq \sup _{r}\|\lambda\|^{\frac{p_{r}}{M}} g(x) \\
\leq\|\lambda\|^{\frac{\rho}{M}} g(x) \rightarrow 0 \text { as } \lambda \rightarrow 0
\end{gathered}
$$

It is quite routine to show that $\operatorname{ces}(p, q)$ is a metric space with the metric $d(x, y)=g(x-y)$ provided that $x, y \in$ $\operatorname{ces}(p, q)$, where $g$ is defined by (2). And using a similar method to that in [3] one can show that $\operatorname{ces}(p, q)$ is complete under the metric mentioned above.

\section{Kothe-Toeplitz Duals}

If $\mathrm{X}$ is a sequence space we define ([2], [5])

$$
\begin{aligned}
& X^{|+|}=X^{\alpha}=\left\{\begin{array}{c}
a=\left(a_{k}\right) \in \omega: \sum_{k}\left|a_{k} x_{k}\right|<\infty, \\
\text { for every } x \in X
\end{array}\right\} \\
& X^{+}=X^{\beta} \\
& =\left\{a=\left(a_{k}\right)\right. \\
& \left.\in \omega: \sum_{k} a_{k} x_{k} \text { is convergent, for every } x \in X\right\}
\end{aligned}
$$

Now we are going to give the following theorem by which the generalized Kothe-Toeplitz dual $\operatorname{ces}^{+}(p, q)$ will be determined.

Theorem 1: If $1<p_{r} \leq \sup _{r} p_{r}<\infty$ and $\frac{1}{p_{r}}+\frac{1}{t_{r}}=$ 1, for $r=0,1,2, \ldots$ then 


$$
\begin{gathered}
\operatorname{ces}^{+}(p, q)=[\operatorname{ces}(p, q)]^{\beta} \\
=\left\{a=\left(a_{k}\right): \sum_{r=0}^{\infty} \begin{array}{c}
\left(Q_{2^{r}} \max \left|\frac{a_{k}}{q_{k}}\right|\right)^{t_{r}} E^{-t_{r}<\infty,} \\
\text { for some integer } E>1
\end{array}\right\} .
\end{gathered}
$$

Proof: $\quad$ Let $\quad 1<p_{r} \leq \underset{r}{\sup } p_{r}<\infty$ and $\frac{1}{p_{r}}+\frac{1}{t_{r}}=$ 1, for $r=0,1,2, \ldots$ Define

$$
\mu(t)=\left\{a=\left(a_{k}\right): \sum_{r=0}^{\infty} \begin{array}{l}
\left(Q_{2^{r}} \max \left|\frac{a_{k}}{q_{k}}\right|\right)^{t_{r}} E^{-t_{r}}<\infty, \\
\text { for some integer } E>1
\end{array}\right\}
$$

We want to show that $\operatorname{ces}^{+}(p, q)=\mu(t)$.

Let $x \in \operatorname{ces}(p, q)$ and $a \in \mu(t)$. Then using inequality (1) we get

$$
\begin{gathered}
\sum_{k=1}^{\infty}\left|a_{k} x_{k}\right|=\sum_{r=0}^{\infty} \sum_{r}\left|a_{k} x_{k}\right| \\
=\sum_{r=0}^{\infty} \sum_{r}\left|\frac{a_{k}}{q_{k}} q_{k} x_{k}\right| \\
=\sum_{r=0}^{\infty} \sum_{r}\left|\frac{a_{k}}{q_{k}}\right|\left|q_{k} x_{k}\right| \\
\leq \sum_{r=0}^{\infty} \max _{r}\left|\frac{a_{k}}{q_{k}}\right| \sum_{r}\left|q_{k} x_{k}\right| \\
=\sum_{r=0}^{\infty} Q_{2^{r}} \max _{r}\left|\frac{a_{k}}{a_{k}}\right| \frac{1}{Q_{2^{r}}} \sum_{r}\left|q_{k} x_{k}\right| \\
\leq E \sum_{r=0}^{\infty}\left\{\left(Q_{2^{r}} \max _{r}\left|\frac{a_{k}}{a_{k}}\right|\right)^{t_{r}} E^{-t_{r}}+\left(\frac{1}{Q_{2^{r}}} \sum_{r}\left|q_{k} x_{k}\right|\right)^{p_{r}}\right\} \\
=E\left\{\sum_{r=0}^{\infty}\left(Q_{2^{r}} \max _{r}\left|\frac{a_{k}}{q_{k}}\right|\right)^{t_{r}} E^{-t_{r}}+\sum_{r=0}^{\infty}\left(\frac{1}{Q_{2^{r}}} \sum_{r}\left|q_{k} x_{k}\right|\right)^{p_{r}}\right\} \\
<\infty
\end{gathered}
$$

which implies that the series $\sum_{k=1}^{\infty} a_{k} x_{k}$ convergent.

Therefore,

$a \in$ dual of $\operatorname{ces}(p, q)=\operatorname{ces}^{+}(p, q)$

This shows, $\mu(t) \subset \operatorname{ces}^{+}(p, q)$

Conversely, suppose that $\sum a_{k} x_{k}$ is convergent for all $x \in \operatorname{ces}(p, q)$ but $a \notin \mu(t)$. Then

$\sum_{r=0}^{\infty}\left(Q_{2^{r}} \max _{r}\left|\frac{a_{k}}{q_{k}}\right|\right)^{t_{r}} E^{-t_{r}}=\infty$, for every integer $E>1$

So we can define a sequence $0=n(0)<n(1)<n(2)<$ such that $\gamma=0,1,2, \ldots$, we have

$$
M_{\gamma}=\sum_{r=n(\gamma)}^{n(\gamma+1)-1}\left(Q_{2^{r}} \max _{r}\left|\frac{a_{k}}{q_{k}}\right|\right)^{t_{r}}(\gamma+2)^{-t_{r} / p_{r}}>1
$$

Now we define a sequence $x=\left(x_{k}\right)$ in the following way:

$$
x_{N(r)}=Q_{2^{r}}^{t_{r}}\left|a_{N(r)}\right|^{t_{r}-1} \operatorname{sgn} a_{N(r)}(\gamma+2)^{-t_{r}} M_{\gamma}^{-1}
$$

for $n(\gamma) \leq r \leq n(\gamma+1)-1, \gamma=0,1,2, \ldots$ and $x_{k}=0$ for $k \neq N(r)$, where $N(r)$ is such that $\left|a_{N(r)}\right|={ }_{r}^{\max }\left|\frac{a_{k}}{a_{k}}\right|$, the maximum is taken with respect to $\mathrm{k}$ in $\left[2^{r}, 2^{r+1}\right)$.

Therefore,

$$
\begin{aligned}
& \sum_{k=2^{n(\gamma)}}^{2^{n(\gamma+1)-1}} a_{k} x_{k}=\sum_{\substack{r=n(\gamma) \\
n(\gamma+1)-1}}^{n(\gamma+1)-1}\left(Q_{2^{r}}\left|a_{N(r)}\right|\right)^{t_{r}}(\gamma+2)^{-t_{r}} M_{\gamma}^{-1} \\
= & M_{\gamma}^{-1}(\gamma+2)^{-1} \sum_{\substack{r=n(\gamma)\\
}}\left(Q_{2^{r}}\left|a_{N(r)}\right|\right)^{t_{r}}(\gamma+2)^{-t_{r} / p_{r}} \\
= & M_{\gamma}^{-1} M_{\gamma}(\gamma+2)^{-1} \\
= & (\gamma+2)^{-1}
\end{aligned}
$$

It follows that

$\sum_{k=1}^{\infty} a_{k} x_{k}=\sum_{\gamma=0}^{\infty}(\gamma+2)^{-1}$ diverges.

Moreover

$$
\begin{aligned}
& \sum_{\substack{r=n(\gamma) \\
n(\gamma+1)-1}}^{n(\gamma+1)-1}\left(\frac{1}{Q_{2}} \sum_{r}\left|q_{k} x_{k}\right|\right)^{p_{r}} \\
= & \sum_{r=n(\gamma)} Q_{2^{r}}^{\left(t_{r}-1\right) p_{r}}\left|a_{N(r)}\right|^{\left(t_{r}-1\right) p_{r}}(\gamma+2)^{-t_{r} / p_{r}} M_{\gamma}^{-p_{r}} \\
\leq & (\gamma+2)^{-2} M_{\gamma}^{-1} \sum_{r=n(\gamma)}^{n(\gamma+1)-1} Q_{2^{r}}^{t_{r}}\left|a_{N(r)}\right|^{t_{r}}(\gamma+2)^{-t_{r} / p_{r}} \\
= & (\gamma+2)^{-2} M_{\gamma}^{-1} M_{\gamma} \\
= & (\gamma+2)^{-2}
\end{aligned}
$$

Therefore

$$
\sum_{r=0}^{\infty}\left(\frac{1}{Q_{2} r} \sum_{r}\left|q_{k} x_{k}\right|\right)^{p_{r}} \leq(\gamma+2)^{-2}<\infty
$$

That is, $x \in \operatorname{ces}(p, q)$ which is a contradiction to our assumption. Hence

$a \in \mu(t)$. That is, $\mu(t) \supset \operatorname{ces}^{+}(p, q)$.

Then combining the two results, we get

$\operatorname{ces}^{+}(p, q)=\mu(t)$.

The continuous dual of $\operatorname{ces}(p, q)$ is determined by the following theorem.

Theorem 2: Let $1<p_{r} \leq \underset{r}{\sup } p_{r}<\infty$. Then continuous dual $\operatorname{ces}^{*}(p, q)$ is isomorphic to $\mu(t)$, which is defined by (3)

Proof: It is easy to check that each $x \in \operatorname{ces}(p, q)$ can be written in the form

$$
x=\sum_{k=1}^{\infty} x_{k} e_{k}, \text { where } e_{k}=(0,0,0, \ldots 0,1,0, \ldots)
$$

and the 1 appears at the $\mathrm{k}$-th place. Then for any $f \in$ $\operatorname{ces}^{*}(p, q)$ we have

$$
f(x)=\sum_{k=1}^{\infty} x_{k} f\left(e_{k}\right)=\sum_{k=1}^{\infty} x_{k} a_{k} .
$$

Where, $f\left(e_{k}\right)=a_{k}$. By theorem 1 , the convergence of $\sum a_{k} x_{k}$ for every $x$ in ces $(p, q)$ implies that $a \in \mu(t)$.

If $x \in \operatorname{ces}(p, q)$ and if we take $a \in \mu(t)$, then by theorem $1, \sum a_{k} x_{k}$ converges and clearly defines a linear functional on $\operatorname{ces}(p, q)$. Using the same kind of argument as in theorem 1 , it is easy to check that 


$$
\sum_{k=1}^{\infty}\left|a_{k} x_{k}\right| \leq E\left(\sum_{r=0}^{\infty}\left(Q_{2^{r}} \max _{r}\left|\frac{a_{k}}{q_{k}}\right|\right)^{t_{r}} E^{-t_{r}}+1\right) g(x)
$$

whenever $g(x) \leq 1$, where $g(x)$ is defined by (2).

Hence $\sum a_{k} x_{k}$ defines an element of $\operatorname{ces}^{*}(p, q)$.

Furthermore, it is easy to see that representation (4) is unique. Hence we can define a mapping

$$
T: \operatorname{ces}^{*}(p, q) \rightarrow \mu(t) .
$$

by $T(f)=\left(a_{1}, a_{2}, \ldots\right)$ where the $a_{k}$ appears in representation (4). It is evident that $T$ is linear and bijective. Hence $\operatorname{ces}^{*}(p, q)$ is isomorphic to $\mu(t)$.

\section{Matrix Transformations}

In the following theorems we shall characterize the matrix classes $\left(\operatorname{ces}(p, q), l_{\infty}\right)$ and $(\operatorname{ces}(p, q), c)$. Let $A=$ $\left(a_{n, k}\right) n, k=1,2, \ldots$ be an infinite matrix of complex numbers and $X, Y$ two subsets of the space of complex sequences. We say that the matrix $A$ defines a matrix transformation from $\mathrm{X}$ into $\mathrm{Y}$ and denote it by $A \in(X, Y)$ if for every sequence $x=\left(x_{k}\right) \in X$ the sequence $A(x)=A_{n}(x)$ is in Y, where

$$
A_{n}(x)=\sum_{k=1}^{\infty} a_{n, k} x_{k}
$$

provided the series on the right is convergent.

Theorem 3: Let $1<p_{r} \leq \underset{r}{\sup } p_{r}<\infty$. Then $A \in$ $\left(\operatorname{ces}(p, q), l_{\infty}\right)$ if and only if there exists an integer $E>1$, such that $U(E)<\infty$. .

Where

$$
U(E)=\sup _{n} \sum_{r=0}^{\infty}\left(Q_{2} r A_{r}(n)\right)^{t_{r}} E^{-t_{r}} \text { and } \frac{1}{p_{r}}+\frac{1}{t_{r}}=1, r=
$$

$0,1,2, \ldots$

Proof: Sufficiency: Suppose there exists an integer $E>1$, such that $U(E)<\infty$. Then by inequality (1), we have

$$
\begin{gathered}
\sum_{k=1}^{\infty}\left|a_{n, k} x_{k}\right|=\sum_{r=0}^{\infty} \sum_{r}\left|\frac{a_{n, k}}{q_{k}} q_{k} x_{k}\right|=\sum_{r=0}^{\infty} \sum_{r}\left|\frac{a_{n, k}}{q_{k}}\right|\left|q_{k} x_{k}\right| \\
\leq \sum_{r=0}^{\infty} Q_{2^{r}} \max _{r}\left|\frac{a_{n, k}}{q_{k}}\right| \frac{1}{Q_{2^{r}}} \sum_{r}\left|q_{k} x_{k}\right| \\
\leq E\left(\sum_{r=0}^{\infty}\left(Q_{2^{r}} A_{r}(n)\right)^{t_{r}} E^{-t_{r}}+\sum_{r=0}^{\infty}\left(\frac{1}{Q_{2^{r}}} \sum_{r}\left|q_{k} x_{k}\right|\right)^{p_{r}}\right) \\
<\infty
\end{gathered}
$$

Therefore, $A \in\left(\operatorname{ces}(p, q), l_{\infty}\right)$.

Necessity: Suppose that $A \in\left(\operatorname{ces}(p, q), l_{\infty}\right)$, but

$\sup _{n} \sum_{r=0}^{\infty}\left(Q_{2^{r}} A_{r}(n)\right)^{t_{r}} E^{-t_{r}}=\infty$ for every integer $E>1$.

Then $\sum_{k=1}^{\infty} a_{n, k} x_{k}$ converges for every $n$ and $x \in$ $\operatorname{ces}(p, q)$, whence $\left(a_{n, k}\right)_{k=1,2, \ldots} \in \operatorname{ces}^{+}(p, q)$ for every $\mathrm{n}$.

By theorem 1, it follows that each $A_{n}$ defined by

$$
A_{n}(x)=\sum_{k=1}^{\infty} a_{n, k} x_{k}
$$

is an element of $\operatorname{ces}^{*}(p, q)$. Since $\operatorname{ces}(p, q)$ is complete and since $\sup _{n}\left|A_{n}(x)\right|<\infty$ on $\operatorname{ces}(p, q)$, by the uniform boundedness principle there exists a number $L$ independent of $n$ and a number $\delta<1$, such that

$$
\left|A_{n}(x)\right| \leq L
$$

for every $n$ and $x \in S[\theta, \delta]$ where $S[\theta, \delta]$ is the closed sphere in $\operatorname{ces}(p, q)$ with centre at the origin $\theta$ and radius $\delta$.

Now choose an integer $G>1$, such that $G \delta^{M}>L$.

Since

$$
\sup _{n} \sum_{r=0}^{\infty}\left(Q_{2^{r}} A_{r}(n)\right)^{t_{r}} G^{-t_{r}}=\infty
$$

there exists an integer $m_{0}>1$, such that

$$
R=\sum_{r=0}^{m_{0}}\left(Q_{2} r A_{r}(n)\right)^{t_{r}} G^{-t_{r}}>1
$$

Define a sequence $x=\left(x_{k}\right)$ as follows:

$$
x_{k}=0 \text { if } k \geq 2^{m_{0}+1}
$$

$$
x_{N(r)}=Q_{2^{r}}^{t_{r}} \delta^{M / p_{r}}\left(\operatorname{sgn} a_{n}, N(r)\right)\left|a_{n, N(r)}\right|^{t_{r}-1} R^{-1} G^{-t_{r} / p_{r}}
$$

and $x_{k}=0$ if $k \neq N(r)$ for $0 \leq r \leq m_{0}$, where $N(r)$ is the smallest integer such that

$$
\left|a_{n, N(r)}\right|=\max _{r}\left|\frac{a_{n, k}}{q_{k}}\right|
$$

Then one can easily show that $g(x) \leq \delta$ but $\left|A_{n}(x)\right|>L$, which contradicts (5). This complete the proof of the theorem.

Corollary 3.1 (see [10]). Let $1<p_{r} \leq \sup _{r} p_{r}<\infty$. Then $A \in\left(\operatorname{ces}(p), l_{\infty}\right)$ if and only if there exists an integer $\mathrm{E}>1$ such that $U(E)<\infty$, where

$$
\begin{gathered}
U(E)=\sup _{n} \sum_{r=0}^{\infty}\left(2^{r} A_{r}(n)\right)^{t_{r}} \text { and } \frac{1}{p_{r}}+\frac{1}{t_{r}}=1, r \\
=0,1,2, \ldots
\end{gathered}
$$

Proof: If $q_{n}=1$ for every $\mathrm{n}$ in the above theorem, then we obtain the result.

Corollary 3.2 (see [9]). Let $1<p<\infty$. Then $A \in$ $\left(\operatorname{ces}_{p}, l_{\infty}\right)$ if and only if $\sup _{n}\left(\sum_{r=0}^{\infty}\left(2^{r} A_{r}(n)\right)^{t}\right)^{1 / t}<$ $\infty$ where $\frac{1}{p}+\frac{1}{t}=1$

Proof: If $q_{n}=1$ and $p_{n}=p$ for all $\mathrm{n}$ in the above theorem, then we get the result.

Theorem 4. Let $1<p_{r} \leq{ }_{r}^{\sup } p_{r}<\infty$. Then $A \in$ $(\operatorname{ces}(p, q), c)$ if and only if

(i) $a_{n, k} \rightarrow \alpha_{k}(n \rightarrow \infty, k$ is fixed $)$ and 
(ii)there exists an integer $E>1$, such that $U(E)<\infty$, where

$$
U(E)=\sup _{n} \sum_{r=0}^{\infty}\left(Q_{2} r A_{r}(n)\right)^{t_{r}} E^{-t_{r}}
$$

and $\frac{1}{p_{r}}+\frac{1}{t_{r}}=1, r=0,1,2, \ldots$

Proof: Necessity. Suppose $A \in(\operatorname{ces}(p, q), c)$. Then $A_{n}(x)$ exists for each $n \geq 1$ and $\operatorname{Lim}_{n \rightarrow \infty} A_{n}(x)$ exists for every $x \in \operatorname{ces}(p, q)$. Therefore by an argument similar to that in theorem 3 we have condition (ii). Condition (i) is obtained by taking $x=e_{k} \in \operatorname{ces}(p, q)$, where $e_{k}$ is a sequence with 1 at the k-th place and zeros elsewhere.

Sufficiency. The conditions of the theorem imply that

$$
\sum_{r=0}^{\infty}\left(Q_{2^{r}} \max _{r}\left|\frac{\alpha_{k}}{q_{k}}\right|\right)^{t_{r}} E^{-t_{r}} \leq U(E)<\infty(7)
$$

By (7) it is easy to check that $\sum_{k} \alpha_{k} x_{k}$ is absolutely convergent for each $x \in \operatorname{ces}(p, q)$. For each $x \in \operatorname{ces}(p, q)$ and $\varepsilon>0$, we can choose an integer $m_{0}>1$, such that

$$
g_{m_{0}}(x)=\sum_{r=m_{0}}^{\infty}\left(\frac{1}{Q_{2^{r}}} \sum_{r}\left|q_{k} x_{k}\right|\right)^{p_{r}}<\varepsilon^{M}
$$

Then by inequality (1), we have

$$
\begin{gathered}
\sum_{k=2^{m_{0}}}^{\infty}\left|a_{n, k}-\alpha_{k}\right|\left|x_{k}\right| \\
\leq E\left(\sum_{r=m_{0}}^{\infty}\left(Q_{2} r B_{r}(n)\right)^{t_{r}} E^{-t_{r}}+1\right)\left(g_{m_{0}}(x)\right)^{1 / M} \\
<E(2 U(E)+1) \varepsilon,
\end{gathered}
$$

where $B_{r}(n)=\max _{r}\left|\frac{a_{n, k}-\alpha_{k}}{q_{k}}\right|$ and

$$
\sum_{r=m_{0}}^{\infty}\left(Q_{2} r B_{r}(n)\right)^{t_{r}} E^{-t_{r}} \leq 2 U(E)<\infty
$$

It follows immediately that

$$
\operatorname{Lim}_{n \rightarrow \infty} \sum_{k=1}^{\infty} a_{n, k} x_{k}=\sum_{k=1}^{\infty} \alpha_{k} x_{k}
$$

This shows that $A \in(\operatorname{ces}(p, q), c)$ which proved the theorem.

Corollary 4.1 (see [10]). Let $1<p_{r} \leq \sup _{r} p_{r}<\infty$. Then $A \in(\operatorname{ces}(p), c)$ if and only if

(i) $a_{n, k} \rightarrow \alpha_{k}(n \rightarrow \infty, k$ is fixed), and

(ii)there exists an integer $\mathrm{E}>1$ such that $U(E)<\infty$, where

$$
\begin{gathered}
U(E)=\sup \sum_{r=0}^{\infty}\left(2^{r} A_{r}(n)\right)^{t_{r}} E^{-t_{r}} \text { and } \frac{1}{p_{r}}+\frac{1}{t_{r}}=1, r \\
=0,1,2, \ldots
\end{gathered}
$$

Proof: If $q_{n}=1$ for all $\mathrm{n}$ in the above theorem, then statements (i) and (ii) follow.

Corollary 4.2 (see [9]). Let $1<p<\infty$. Then $A \in$ $\left(\mathrm{ces}_{p}, c\right)$ if and only if

(i) $a_{n, k} \rightarrow \alpha_{k}(n \rightarrow \infty, k$ is fixed $)$, and

(ii) ${ }_{n}^{\text {sup }}\left(\sum_{r=0}^{\infty} 2^{r t} A_{r}^{t}(n)\right)^{1 / t}<\infty$, where $\frac{1}{p}+\frac{1}{t}=1$.

Proof: If $q_{n}=1$ and $p_{n}=p$ for all $\mathrm{n}$ in the above theorem, then we get the results.

Corollary 4.3. Let $1<p_{r} \leq \sup _{r}<\infty$. Then $A \in$ $\left(\operatorname{ces}(p, q), c_{0}\right)$ if and only if

- the condition of Theorem 3 holds, and

- $a_{n, k} \rightarrow 0(n \rightarrow \infty, k$ is fixed $)$, where $c_{0}$ is the space of all null sequences.

\section{References}

[1] Amit Maji, P. D. Srivastava, On operator ideals using weighted Cesaro sequence space. Journal of the Egyptian Mathematical Society. (2013)1-7

[2] B. Choudhury and S. K. Mishra, On Kothe-Toeplitz duals of certain sequence spaces and their matrix transformations, Indian J. pure appl. Math, 24(15), 291-301, May 1993.

[3] F. M. KHAN and M. F. RAHMAN, Infinite matrices and Cesaro sequence spaces, Analysis Mathematica, 23(1997), 311 .

[4] G. M. Leibowitz, A note on the Cesaro sequence spaces, Tamkang J. of Math., 2(1971), 151-157.

[5] H. Kizmaz, Canadian Math. Bull. 24(2) (1981), 169-176.

[6] I, J. MADDOX, continuous and Köthe-Toeplitz dual of certain sequence spaces, Proc. Camb. phil. Soc., 65(1969), 431-435.

[7] I, J. MADDOX, Elements of Functional Analysis, Cambridge University Press Cambridge, second edition, 1988.

[8] J, S. Shiue, On the Cesaro sequence spaces, Tamkang J. of Math. 1(1970), 19-25.

[9] K. P. LIM, Matrix transformation in the Cesaro sequence spaces, Kyungpook Math. J. , 14(1974),221-227

[10] K. P. LIM, Matrix transformation on certain sequence space, Tamkang J. of Math. 8(1977), 213-220.

[11] P. D. Johnson Jr. and R. N. Mohapatra, Density of finitely non-zero sequences in some sequence spaces, Math. Japonica 24, No. 3(1979), 253-262. 